\title{
Spectrum of Ocular Firework Injuries in Children: A 5 Year Retrospective Study during a Festival Season Attending Tertiary Healthcare Referral Centre
}

\author{
Dr. Chirag Banker ${ }^{1}$, Dr. Mansi Gondaliya ${ }^{2}$ \\ Gujarat University, M and J Institute of Ophthalmology, 9,New Arunoday Soceity, Near Shivaji park society, opp. Kubereshwar Temple, \\ Saijpur Ahmedabad 382345
}

Gujarat University, M and J Institute of Ophthalmology, 40, Dhruv, Gopalnagar,Main Road, Joshipura, Junagadh362002

\begin{abstract}
Ocular trauma is a major cause of acquired monocular blindness in children. Firework injuries account for $20 \%$ of ocular trauma, can result in considerable ocular morbidity and lead to permanent blindness. This is an avoidable cause of blindness. The purpose of our study was to document the profile of ocular firework injuries in children during the festive season of Diwali and to determine the prevalence of unilateral blindness in them. Awareness needs to be created, and changes in policy regarding sales and handling of firecrackers including mandatory use of protective eyewear should be considered.
\end{abstract}

Keywords: Firework injury, ocular firework injury, unilateral blindness,Festival season,Legislation

\section{Introduction}

Fireworks have an important role in various celebrations and festivals in most parts of the world. Fireworks are an integral part of most celebrations in India. Ocular injuries constitute about $20 \%$ of firework injuries. Trauma is one of the major causes of unilateral avoidable blindness in children.It is estimated that worldwide 160,000-280,000 children under the age of 15 years sustain ocular injuries every year. However, only $5 \%$ of ocular injuries usually require admission. Hence, the actual incidence of pediatric ocular trauma worldwide is much higher amounting to 3.3-5.7 million annually. With vision 2020 giving high priority to avoidable blindness, especially in children, every attempt should be made to prevent such injuries and blindness in children.

During this festival season, we find a dramatic increase in the number of patients with ocular injuries due to fireworks, presenting to the emergency department (ED). Visual impairment and disability in children can be a financial burden on the family and society.

We conducted this retrospective study to document the profile of ocular firework injuries and visual outcome in children treated during the festive season of Diwali over 5 years. The purpose of our study was to find the prevalence of unilateral blindness in these children.

\section{Materials and Methods}

A retrospective chart analysis of ocular firework injury in children during the festival of Diwali from 2010 to 2015, conducted in a tertiary care eye center in Gujarat state. Children below 18 years of age with ocular firework injuries who presented to the emergency department for 3 consecutive days - the day of Diwali, 1 day before, and 1 day after Diwali - were included in this study. The study was conducted in a tertiary care eye center in Gujarat. We did a retrospective analysis of the medical records of children who presented to hospital during the Diwali season for 5 consecutive years. The study was conducted after obtaining the approval of Institutional Review and Ethics Board. All patients underwent complete ophthalmological evaluation. Visual acuity (VA) was tested using Snellen chart or Cardiff acuity cards or finger counting. A complete slit lamp biomicroscopic examination and fundus examination were done in all patients at the time of presentation and on follow up. All patients who sustained open globe injuries underwent preoperative imaging of the eye and orbit to rule out retained foreign bodies. The details of management were recorded. Surgical intervention, when indicated, was done within 24 hour of presentation. Demographic data of all the patients, the nature and site of injury, the initial and final VA, and the intervention done were noted. The causes of severe visual loss and blindness were also recorded. Poor visual outcome was defined as vision $<6 / 60$ and unilateral blindness as $<3 / 60$ in the injured eye. Frequency and percentage were calculated for categorical variables, and mean \pm standard deviation for continuous variables. Data were collated and analyzed using SPSS version 20 (IBM SPSS Statistics for Windows, Version 20.0. Armonk, NY: IBM Corp).

\section{Results}

Eighty-four children presented with ocular injuries due to fireworks over 3 consecutive days during the Diwali season between 2010 and 2015. The age and gender distribution are given in Fig. 1. 


\section{International Journal of Science and Research (IJSR) \\ ISSN (Online): 2319-7064}

Index Copernicus Value (2013): 6.14 | Impact Factor (2014): 5.611

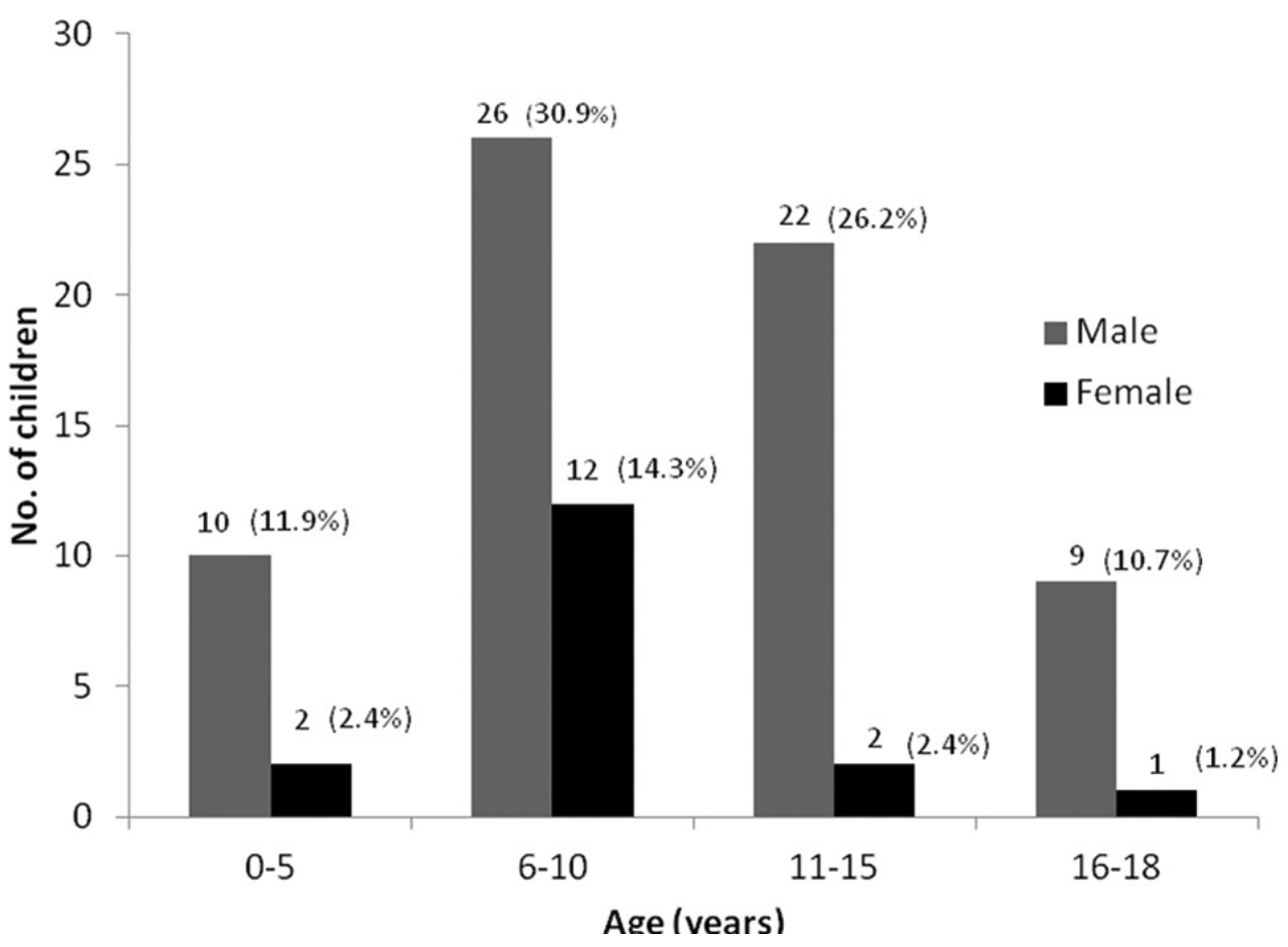

Eighty percentage were male. The mean age of boys was 9.8 \pm 4.2 years and that of girls $8.4 \pm 3.2$ years. $56.5 \%$ of ocular injuries were sustained by boys aged $6-15$ years.

documented in 32 children $(38.1 \%)$. The spectrum of eye involvement in the children in our study is summarized in Table 1.

Twenty-six children (31\%) had bilateral involvement. History regarding the type of firecracker was not

Table 1

\begin{tabular}{|c|c|c|c|c|}
\hline Site of injury & $\begin{array}{l}\text { Closed globe injury } \\
\qquad=79\end{array}$ & & $\begin{array}{c}\text { Open globe injury } \\
n=5\end{array}$ & \\
\hline \multirow[t]{4}{*}{ Lid adnexa } & Lid burns & 36 & Lid tear & 1 \\
\hline & Lid tear & 1 & & \\
\hline & Ectropion & 1 & & \\
\hline & Orbit foreign body & 1 & & \\
\hline \multirow[t]{12}{*}{ Anterior segment } & Conjuctival tear & 6 & Conjuctival tear & 2 \\
\hline & Epithelial defect & 63 & Epithelial defect & 2 \\
\hline & Corneal foreign body & 32 & Corneal foreign body & 1 \\
\hline & Corneal edema & 14 & Corneal edema & 4 \\
\hline & Hyphema & 20 & Hyphema & 4 \\
\hline & Anterior uveitis & 31 & Anterior uveitis & 4 \\
\hline & Iridodialysis & 6 & Corneal tear & 1 \\
\hline & Lens subluxation/zonular dialysis & 5 & Corneoscleral tear & 2 \\
\hline & Traumatic cataract & 10 & Scleral tear & 2 \\
\hline & Angle recession & 5 & Iofb & 1 \\
\hline & Secondary glaucoma & 3 & Zd/lens subluxation & 1 \\
\hline & & & Traumatic cataract & 3 \\
\hline \multirow[t]{6}{*}{ Posterior segment } & Berlins edema & 10 & Vitreous hemorrhage & 2 \\
\hline & Retinal tear & 2 & Iofb & 2 \\
\hline & Choroidal rupture & 1 & Retinal tear & 1 \\
\hline & Vitreous hemorrhage & 6 & & \\
\hline & Macular hole/scar & 4 & & \\
\hline & Epiretinal membrane & 1 & & \\
\hline
\end{tabular}

The most common site of injury was the cornea, which was affected in $51(60.7 \%)$ children. Twenty-four (28.6\%) children had lid and adnexal injury, $56(66.7 \%)$ had anterior segment, and $17(20.2 \%)$ had posterior segment involvement. Among the 84 children who presented to us, $37(44 \%)$ required hospitalization. Parents of six children requested for discharge against medical advice. Among the remaining 31 inpatients, five had penetrating trauma to the globe, and three had intraocular foreign bodies.

All open globe injuries were managed surgically. All children with closed globe injuries who were treated as inpatients were managed conservatively, except for one 


\section{International Journal of Science and Research (IJSR) \\ ISSN (Online): 2319-7064 \\ Index Copernicus Value (2013): 6.14 | Impact Factor (2014): 5.611}

child who underwent a superficial corneal foreign body removal under general anesthesia.

Ten children with closed globe injury had a traumatic cataract at presentation. Six of them underwent lens matter aspiration with intraocular lens implantation. Among the remaining four, one child had angle recession and anterior subluxation of the lens with corneal edema. He underwent lens matter aspiration and partial anterior vitrectomy but was left aphakic due to corneal edema and macular scar. Another child had iridodialysis, secondary glaucoma with corneal edema, and cataract. He underwent trabeculectomy, iridodialysis repair, and lens matter aspiration. Intraocular lens was not placed due to corneal edema. One child had cataract surgery with lens implantation but had poor vision due to choroidal rupture. Another child with cataract and macular scar was lost to follow up. VA at presentation ranged from $6 / 6$ to perception of light (PL). The mean duration of follow- up was 1.5 months. Final visual outcome is summarized in Table 2. Poor visual outcome was taken as vision $<6 / 60$ in the injured eye.

\begin{tabular}{|l|l|l|l|l|l|}
\cline { 3 - 6 } \multicolumn{2}{c}{} & \multicolumn{2}{l|}{ Closed globe injury } & \multicolumn{2}{l|}{ Open globe injury } \\
\hline Who classification & VA categories & Initial VA & Final VA & Initial VA & Final VA \\
\hline \multirow{3}{*}{ Normal } & $6 / 6$ & 21 & 68 & 0 & 0 \\
\cline { 2 - 6 } & $6 / 9-6 / 18$ & 42 & 25 & 0 & 1 \\
\hline \multirow{3}{*}{ Visual impairment } & $6 / 24-6 / 60$ & 10 & 05 & 0 & 0 \\
\cline { 2 - 6 } & $5 / 60-3 / 60$ & 04 & 01 & - & 0 \\
\hline \multirow{3}{*}{ Blindness } & $<3 / 60-p 1$ & 17 & 06 & 3 & 1 \\
\cline { 2 - 6 } & No pl & 0 & 0 & 0 & 3 \\
\cline { 2 - 6 } & Not recorded & 11 & - & 2 & - \\
\hline
\end{tabular}

After either surgical or medical intervention, $77.5 \%$ (93 eyes) had the good visual outcome (6/18 or better). Of the five open globe injuries, four had a poor visual outcome. Only one child with open globe injury with a foreign body within the lens had a good visual outcome. The prevalence of unilateral blindness in our study was $8 \%$ (95\% confidence interval - 2-13\%), with 10 children having final VA worse than $3 / 60$. The causes of unilateral blindness are mentioned in Table 3.

Table 3: Causes of unilateral blindness following firecracker

\begin{tabular}{|c|c|c|c|}
\hline CASE & age/sex & Final VA & Complications \\
\hline 1 & $11 /$ male & No PL & $\begin{array}{c}\text { Extrusion of contents resulting in } \\
\text { Evisceration }\end{array}$ \\
\hline 2 & $05 /$ male & No PL & Phthisis bulbi \\
\hline 3 & $10 /$ female & No PL & $\begin{array}{c}\text { Total retinal detachment, Phthisis } \\
\text { bulbi }\end{array}$ \\
\hline 4 & $04 /$ male & PL + & Dense amblyopia \\
\hline 5 & $10 /$ male & CF 5m & Decompensated cornea \\
\hline 6 & $10 /$ female & PL+ & Traumatic optic neuropathy \\
\hline 7 & $12 /$ male & PL+ & Retinal detachment sequelae \\
\hline 8 & $3 /$ male & CFNF & Choroidal rupture \\
\hline 9 & $10 /$ male & CFNF & $\begin{array}{c}\text { Decompensated cornea, scar at } \\
\text { macula }\end{array}$ \\
\hline 10 & $2 /$ male & PL+ & $\begin{array}{c}\text { Retinitis sclopetaria, Choroidal } \\
\text { rupture }\end{array}$ \\
\hline
\end{tabular}

On follow-up, many children were noted to have long-term complications, which could potentially compromise vision. Five children had angle recession and three who developed secondary glaucoma are on regular follow-up. One child was a steroid responder but was lost to follow-up. Two children developed a traumatic macular hole, and epiretinal membrane was seen in one child. One child with severe facial burns developed lower lid cicatricial ectropion which was managed surgically.

\section{Discussion}

Injuries to the eye and adnexa constituted about 20\% of firecracker injuries. Many studies have reported on ocular injuries caused by firecrackers. However, there have not been any study focusing on ocular firework injuries in the pediatric age group. Kuhn et al. found that up to $61 \%$ of firecracker injuries were sustained by children. Boys in the age group of $6-10$ years constituted the majority $(56.5 \%)$ of cases in our study. This is similar to the results of the study by Wilson. Marilyn et al. reported one third of permanent blindness among children who sustained ocular injury due to fireworks. In contrast, in our study, only three children $(5.1 \%)$ with ocular injuries did not have even PL while 10 $(11.9 \%)$ children had vision worse than $3 / 60$ in the injured eye. Our study demonstrates the magnitude of severe ocular morbidity and loss of vision in children due to firecracker injuries.

According to the literature, only 5\% of injuries required Hospitalization, while $44 \%$ in our study needed inpatient care. Vision loss in children causes a huge burden to the family as well as society. Firecracker injury is a preventable cause of vision loss in children. Social awareness plays a key role in preventing such injuries. Awareness needs to be created among children by parents and teachers, regarding the possible danger of injury from firecrackers and about the careful handling of these devices. This can be accomplished through school education programs and media campaigns via television, radio, and newspapers. The importance of strict parental supervision during these celebrations also needs to be emphasized. However, effective legislation Is lax in India. The Central Pollution Control Board estimates that $95 \%$ of firecrackers violate noise and pollution norms. It is high time that stringent legislative measures are Implemented by government. Many countries have used legislative measures to regulate the use of fireworks. Implementation of similar legislative measures would go a long way in reducing firework related injuries in India. Children should handle firecrackers only under adult supervision. Protective eyewear should be made compulsory

\section{Volume 4 Issue 12, December 2015}




\section{International Journal of Science and Research (IJSR) \\ ISSN (Online): 2319-7064}

Index Copernicus Value (2013): 6.14 | Impact Factor (2014): 5.611

and available in the market along with firecrackers. Regulations for the safe handling of these devices should be introduced and implemented to prevent further such injuries in the future.

\section{Limitation of Our Study}

We included only children who sustained firecracker injury during 3 consecutive days around Diwali. We did not include those who presented later or during other festive seasons. This may have resulted in underestimation of the problem. As this was a retrospective study, we could not gather accurate information on preinjury vision, parental supervision, or the type of firecracker that caused maximal ocular damage.

\section{Conclusion}

Ocular firework injuries that occur in children can result in considerable ocular morbidity and lead to permanent blindness. Assuming all eyes had a good vision before trauma, 1 out of 12 children injured by firecrackers in our study became blind unilaterally. It is imperative that adequate measures are taken through public education and legislation to ensure that celebrations involving fireworks are conducted in a safe manner to prevent ocular injuries and visual loss, especially in children.

\section{Acknowledgement}

It is pleasant privilege on my part to express my most cordial and deepest sense of gratefulness to my teachers DR.VIPUL PRAJAPATI M.S.,ASSISTANT PROFESSOR OF OPTHALMOLOGY,M \& J INSTITUTE OF OPHTHALMOLOGY, DR. ALKA SHAH M.S.,ASSOCIATE PROFESSOR OF OPTHALMOLOGY, $M$ \& J INSTITUTE OF OPHTHALMOLOGY for their untiring and precious guidance, sympathetic supervision, heartily assistance and constructive motivation in every phase during entire period of work.

I am highly indebted and thankful to Dr. Hansa Thakkar SHAH M.S.,ASSOCIATE PROFESSOR OF OPTHALMOLOGY, $\mathrm{M} \& \mathrm{~J}$ INSTITUTE OF OPHTHALMOLOGY for his constant inspiration and support during my residential carrier.

I am thankful to all my teachers of $M \& J$ Institute of ophthalmology for their support and encouragement.

I am thankful to all my colleagues and staff members of this institute who helped me directly or indirectly whenever required in my tenure.

\section{References}

[1] American Academy of Pediatrics: Committee on Injury and Poison Prevention. Fireworks related injuries to children. Pediatrics 2001;108:190-1.

[2] Witsaman RJ, Comstock RD, Smith GA. Pediatric fireworks related injuries in the United States: 1990-2003. Pediatrics 2006;118:296-303.
[3] Abbott J, Shah P. The epidemiology and etiology of pediatric ocular trauma. Surv Ophthalmol 2013;58:476-85.

[4] Roodhooft JM. Leading causes of blindness worldwide. Bull Soc Belge Ophtalmol 2002;283:1925.

[5] Bandrakalli P, Ganekal S, Jhanji V, Liang YB, Dorairaj S. Prevalence and causes of monocular childhood blindness in a rural population in Southern India. J Pediatric Ophthalmic Strabismus 2012;49:303-7.

[6] Gilbert C, Foster A. Childhood blindness in the context of vision 2020 - The right to sight. Bull World Health Organ 2001;79:227-32.

[7] Kuhn FC, Morris RC, Witherspoon DC, Mann L, Mester V, Módis L, et al. Serious fireworks related eye injuries. Ophthalmic Epidemiol 2000;7:139-48.

[8] Berger LR, Kalishman S, Rivara FP. Injuries from fireworks. Pediatrics 1985;75:877-82.

[9] Smith GA, Knapp JF, Barnett TM, Shields BJ. The rockets' red glare, the bombs bursting in air: Fireworks-related injuries to children. Pediatrics 1996;98:1-9.

[10] Lee RT. Fire-cracker injury to the eyes in Hong Kong. Br J Ophthalmol 1966;50:666-9.

[11] Dhir SP, Shishko MN, Krewi A, Mabruka S. Ocular fireworks injuries in children. J Pediatr Ophthalmol Strabismus 1991;28:354-5.

[12] Sundelin K, Norrsell K. Eye injuries from fireworks in Western Sweden. Acta Ophthalmol Scand 2000;78:61-4.

[13] Thygesen J. Ocular injuries caused by fireworks 25 years of experience with preventive campaigns in Denmark. Acta Ophthalmol Scand 2000;78:1-2.

[14] Levitz LM, Miller JK, Uwe M, Drüsedau H. Ocular injuries caused by fireworks. J AAPOS 1999;3:317-8.

[15] Mansouri MR, Mohammadi SF, Hatef E, Rahbari H, Khazanehdari MS, Zandi $\mathrm{P}$, et al. The Persian Wednesday eve festival "Charshanbe-Soori" fireworks eye injuries: A case series. Ophthalmic Epidemiol 2007;14:17-24.

[16] Knox FA, Chan WC, Jackson AJ, Foot B, Sharkey JA, McGinnity FG. A British ophthalmological surveillance unit study on serious ocular injuries from fireworks in the UK. Eye (Lond) 2008;22:944-7.

[17] Kumar R, Puttanna M, Sriprakash KS, Sujatha Rathod BL, Prabhakaran VC. Firecracker eye injuries during Deepavali festival: A case series. Indian J Ophthalmol 2010;58:157-9.

[18] Wisse RP, Bijlsma WR, Stilma JS. Ocular firework trauma: A systematic review on incidence, severity, outcome and prevention. $\mathrm{Br} \mathrm{J}$ Ophthalmol 2010;94:1586-91.

[19] Wilson RS. Ocular fireworks injuries and blindness. An analysis of 154 cases and a three state survey comparing the effectiveness of model law regulation. Ophthalmology 1982;89:291-7. 


\begin{abstract}
Abbreviations
ED-emergency department

VA-Visual acuity

PL- Perception of light

WHO- World Health Organization

CFNF- Counting fingers near face
\end{abstract}

\title{
Author Profile
}

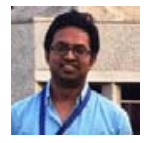

Dr Chirag Banker received M.B.B.S degree from S.B.K.S medical college Waghodiya and doing M.S. Ophthalmology degree from $M$ \& $J$ institute of ophthalmology, B.J. Medical College Ahmedabad. Currently working as third year resident in $M \& J$ institute of Ophthalmology.

Dr. Mansi Gondaliya received M.B.B.S degree from V.S Medical college Ahmedabad and doing Diploma in Ophthalmology from M \& J institute of ophthalmology, B.J. Medical College Ahmedabad. Currently working as Second year resident in M \& J institute of Ophthalmology. 